\title{
Shear strengthening of reinforced concrete continuous beams
}

1 Saeed Ahmad PhD

Professor, University of Engineering and Technology Taxila, Pakistan

2 Ayub Elahi PhD

Assistant Professor, University of Engineering and Technology Taxila, Pakistan
3. Salim Barbhuiya MEng, PhD

Research Associate, School of Engineering, University of the West of Scotland, Paisley, UK

4 Abdul Ghaffar MSC

Postgraduate Student, University of Engineering and Technology Taxila, Pakistan
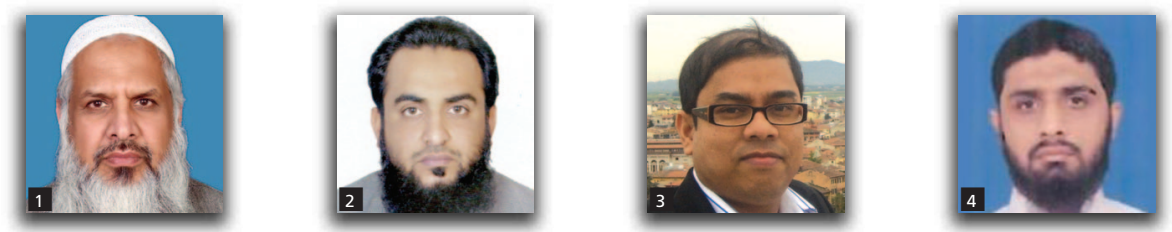

This paper presents the results of an experimental investigation to evaluate the contribution of carbon-fibrereinforced polymer sheets in enhancing the shear strength of continuous reinforced concrete beams. A total of five, two-span concrete continuous beams with rectangular cross-section were tested. One beam without strengthening was used as the control and the other four beams were strengthened with different arrangements of polymer sheets. The variables selected were various wrapping schemes and anchorage length of the polymer sheet. The aim was to develop a better understanding of the shear contribution of polymer and to investigate the potential for cost savings by minimising the area of externally bonded polymer sheets. Test results were compared with four existing shear prediction models available in the literature. The results indicate that the polymer sheet significantly enhanced the shear strength of the beams, and that the area of polymer sheet can be minimised with marginal compromise on the shear carrying capacity of strengthened concrete beams.

\section{Notation}

a shear span, distance between point load and face of support

a/d shear span to effective depth ratio

$b_{\mathrm{w}} \quad$ beam width

$d \quad$ effective depth of specimen

$d_{\mathrm{s}} \quad$ effective depth of CFRP

$E_{\mathrm{f}} \quad$ elastic modulus of CFRP

$f_{\mathrm{c}}^{\prime} \quad$ cylindrical compressive strength of concrete

$f_{\text {fu }} \quad$ CFRP ultimate tensile strength

$h \quad$ total depth of specimen

$h_{\mathrm{f}} \quad$ depth of CFRP sheet

$P_{\mathrm{u}} \quad$ load at failure

$R_{\mathrm{B}} \quad$ reduction factor according to Bukhari et al. (2010)

$R_{\exp } \quad$ reduction factor according to this experimental study

$R_{\mathrm{K}} \quad$ reduction factor according to Khalifa et al. (1998)

$R_{\mathrm{T}} \quad$ reduction factor according to Triantafillou and Antonopoulos (2000)

$R_{\mathrm{TR} 55}$ reduction factor according to report TR55 (Concrete Society, 2004)

$R_{\mathrm{Z}} \quad$ reduction factor according to Zhang and Hsu (2005)

$s_{\mathrm{f}} \quad$ spacing of CFRP reinforcement $t_{\mathrm{f}} \quad$ thickness of CFRP reinforcement

$V_{\mathrm{c}} \quad$ shear strength of concrete

$V_{\exp } \quad$ experimental shear strength of RC beam

$V_{\mathrm{f}} \quad$ shear strength contribution by external fibre reinforced polymer composite

$V_{\mathrm{fB}} \quad$ theoretical shear strength of CFRP according to Bukhari et al. (2010)

$V_{\mathrm{fK}} \quad$ theoretical shear strength of CFRP according to Khalifa et al. (1998)

$V_{\mathrm{fT}} \quad$ theoretical shear strength of CFRP according to Triantafillou and Antonopoulos (2000)

$V_{\text {fTR55 }}$ theoretical shear strength of CFRP according to report TR55 (Concrete Society, 2004)

$V_{\mathrm{fZ}} \quad$ theoretical shear strength of CFRP according to Zhang and Hsu (2005)

$V_{\mathrm{n}} \quad$ nominal shear strength of RC

$V_{\mathrm{s}} \quad$ shear strength due to internal steel stirrups

$w_{\mathrm{f}} \quad$ width of CFRP reinforcement

$z_{\mathrm{f}} \quad$ lever arm

$\beta \quad$ CFRP orientation with respect to the longitudinal axis of the beam

$\varepsilon_{\mathrm{fu}} \quad$ ultimate tensile strain of CFRP reinforcement 


\author{
$\varepsilon_{\mathrm{fe}} \quad$ effective strain \\ $\varepsilon_{\mathrm{fke}} \quad$ characteristic effective strain of CFRP reinforcement \\ $\rho_{\mathrm{f}} \quad$ CFRP shear reinforcement ratio \\ $\rho_{\mathrm{f}} E_{\mathrm{f}} \quad$ axial rigidity of CFRP reinforcement \\ $\rho_{1} \quad$ longitudinal reinforcement ratio
}

\section{Introduction}

Structures require strengthening for various reasons, such as deterioration, structural damage, increased design loads, structural modifications, changes in design codes and errors in design and construction. Fibre-reinforced polymer (FRP) composites are widely used for strengthening concrete structures because they have many advantages over conventional strengthening methods (Berset, 1992; Uji, 1992). Most published research work has focused on the flexural performance of concrete beams strengthened with FRP composites (Duthinh and Starnes, 2004; Hassan and Rizkalla, 2004). As shear failure in concrete beams is catastrophic and occurs with little or no advance warning, there is a need for better understanding of this complex failure mechanism in reinforced concrete (RC) beams. The vast majority of previous research (e.g. Al-Amerya and Al-Mahaidi, 2006; Chajes et al., 1995) has focused on investigating shear strengthening of simply-supported, single-span RC beams using carbon-fibrereinforced polymer (CFRP) composites. Only a few studies on continuous RC beams using CFRP sheets applied at various anchorage lengths and locations are reported in the literature.

Previous experimental studies (Chen and Teng, 2002; Khalifa and Nanni, 2002; Malek and Saadatmanesh, 1998; Triantafillou, 1998) have shown that FRP composites are effective in increasing the shear capacity of concrete beams. However, despite numerous interesting studies, the shear behaviour of RC beams strengthened with FRP has not yet been thoroughly investigated, and the test database (ACI, 1996, 2002) is insufficient to produce comprehensive design guidance. The most commonly used FRP configuration schemes include complete side wrap, U-wrap or full wrapping of the section using CFRP sheet but, in practice, beams are frequently cast monolithically with the top slab, thus excluding full wrapping as a feasible option. Moreover, situations may arise where only a part of the beam needs strengthening.

Continuous RC beams, a fairly common structural element of any structure, behave differently from simply supported beams. In continuous beams, the points of maximum negative moment and shear coincide (Figure 1), and the point of inflection may be close to the point of critical shear. By ignoring these differences during design one reduces the potential available strength, which may lead to severe cracking. These conditions make most empirical equations (developed for simply supported beams) useless for continuous beams. However, very little research has been published in connection with the behaviour of such continuous beams with external reinforcement (Ashour et al., 2004; Bukhari et al., 2010). In addition, most design guidelines (ACI, 1996; Concrete Society, 2000) were developed for simply supported beams with external FRP laminates.
This paper presents the results of an experimental investigation aimed at rectifying some of the deficiencies in the existing database by contributing to the understanding of continuous RC beams strengthened in shear with CFRP sheets. Test data were analysed and compared with four FRP strength prediction models available in the literature (Concrete Society, 2004; Khalifa et al., 1998; Triantafillou and Antonopoulos, 2000; Zhang and Hsu, 2005) and a model proposed by Bukhari et al. (2010).

\subsection{Review of models for FRP strengthening in shear}

The current American Concrete Institute (ACI, 2002) and International Federation for Structural Concrete (fib, 2001) design guidelines for strengthening $\mathrm{RC}$ beams in shear with CFRP are based on empirical design equations derived by Khalifa et al. (1998) and Triantafillou and Antonopoulos (2000), respectively. The nominal shear strength, $V_{\mathrm{n}}$, can be calculated by simply adding the individual contributions of the concrete, $V_{\mathrm{c}}$, internal steel stirrups, $V_{\mathrm{s}}$, and external FRP composites, $V_{\mathrm{f}}$, resulting in the general equation

1. $V_{\mathrm{n}}=V_{\mathrm{c}}+V_{\mathrm{s}}+V_{\mathrm{f}}$

where $V_{\mathrm{c}}$ is the shear strength of a beam without stirrups and $V_{\mathrm{s}}$ is calculated with a $45^{\circ}$ truss. The shear contribution of externally bonded FRP reinforcement is calculated analogously to that of internal steel stirrups. Triantafillou (1998) proposed that the contribution of the FRP sheet to shear strength of a RC beam, $V_{\mathrm{f}}$, is given by

\section{2. $V_{\mathrm{f}}=\rho_{\mathrm{f}} E_{\mathrm{f}} \varepsilon_{\mathrm{fe}} b_{\mathrm{w}} z_{\mathrm{f}}(1+\cot \beta) \sin \beta$}

where $\rho_{\mathrm{f}}$ (CFRP shear reinforcement ratio) is equal to $2 t_{\mathrm{f}} w_{\mathrm{f}} / b_{\mathrm{w}} s_{\mathrm{f}}$, $E_{\mathrm{f}}$ is the elastic modulus of CFRP, $b_{\mathrm{w}}$ is the beam width, $t_{\mathrm{f}}$ is the thickness of CFRP reinforcement, $w_{\mathrm{f}}$ is its width and $s_{\mathrm{f}}$ is the spacing of CFRP, which becomes equal to $w_{\mathrm{f}}$ for a continuous vertical CFRP reinforcement. The angle $\beta$ describes the fibre orientation with respect to the longitudinal axis of the beam. The lever arm, $z_{\mathrm{f}}$, is taken as $0 \cdot 9 d_{\mathrm{f}}$ in Eurocode format (BSI, 2004) or $d_{\mathrm{f}}$ in ACI format (ACI, 2002) where $d_{\mathrm{f}}$ is the effective depth of the FRP reinforcement measured from the centre of the tensile steel. In the current paper, $d_{\mathrm{f}}$ is measured to the extreme compressive fibre of the FRP when the FRP does not extend over the full height of the beam.

The CFRP design stress is calculated in terms of an effective strain, $\varepsilon_{\mathrm{fe}}$, which is given by

\section{3. $\varepsilon_{\mathrm{fe}}=R \varepsilon_{\mathrm{fu}}$}

where $R$ is a reduction factor and $\varepsilon_{\mathrm{fu}}$ is the ultimate tensile strain of CFRP. The stress in the CFRP is calculated using $\varepsilon_{\mathrm{fe}}$ instead of $\varepsilon_{\mathrm{fu}}$ since CFRP-strengthened RC beams tend to fail due to 
debonding of the CFRP sheet from the concrete surface or by fracture of the sheet at a lower tensile strain than the ultimate breaking strain of naked CFRP.

Triantafillou (1998) rearranged Equation 2 to give the FRP effective strain in terms of $V_{\mathrm{f}}$ and found that $\varepsilon_{\mathrm{fe}}$ is a function of the axial rigidity $\left(\rho_{\mathrm{f}} E_{\mathrm{f}}\right)$ of FRP. He went on to derive an empirical relationship between strain and axial rigidity using data from 40 beams tested by various researchers.

Khalifa et al. (1998) modified the Triantafillou (1998) method for calculating $\varepsilon_{\mathrm{fe}}$ on the basis of a slightly enlarged database of 48 beams. The experimental data used by Khalifa et al. (1998) included two types of FRP materials (carbon and aramid) and three different wrapping configurations (sides only, U-shaped and complete wrapping), with both continuous sheets and strips of FRP. Khalifa et al. (1998) derived equations from a regression analysis of test data including both FRP rupture and debonding failure modes. They proposed that the design shear strength should be obtained by multiplying each component of the nominal shear strength by strength reduction factors equal to 0.85 for $V_{\mathrm{c}}$ and $V_{\mathrm{s}}$ and 0.70 for $V_{\mathrm{f}}$.

Triantafillou and Antonopoulos (2000) presented equations for $\varepsilon_{\mathrm{fe}}$ derived from a regression analysis of data from 75 beam tests.
They also derived two different equations to calculate the characteristic effective strain $\left(\varepsilon_{\mathrm{fke}}=0 \cdot 8 \varepsilon_{\mathrm{fe}}\right)$ for CFRP sheet for different configurations.

Triantafillou and Antonopoulos (2000) proposed that, in Eurocode format, $\varepsilon_{\mathrm{fke}}$ should be used in Equation 2 in conjunction with a partial factor of safety of 1.3 if FRP debonding governs (i.e. for side or $\mathrm{U}$ wraps) or 1.2 if fracture governs (i.e. fully wrapped).

In 2004, the Concrete Society published revised guidelines for strengthening beams in shear with FRP in the second edition of TR55 (Concrete Society, 2004). The revised guidelines are based on the work of Denton et al. (2004) and superseded the original recommendations in TR55, which were derived from the work of Khalifa et al. (1998). The effective strain in the FRP is taken as the least of three different expressions. According to TR55, the first strain limit represents the average FRP strain when fracture occurs. The second strain limit corresponds to debonding of FRP and the third limit is based on experience and is intended to limit the loss of aggregate interlock due to excessive crack widths. The design stress in the FRP is obtained by multiplying the effective strain by the design elastic modulus, which equals the characteristic value divided by a partial factor of safety that depends on the FRP type and method of application and is typically around $1 \cdot 2$.

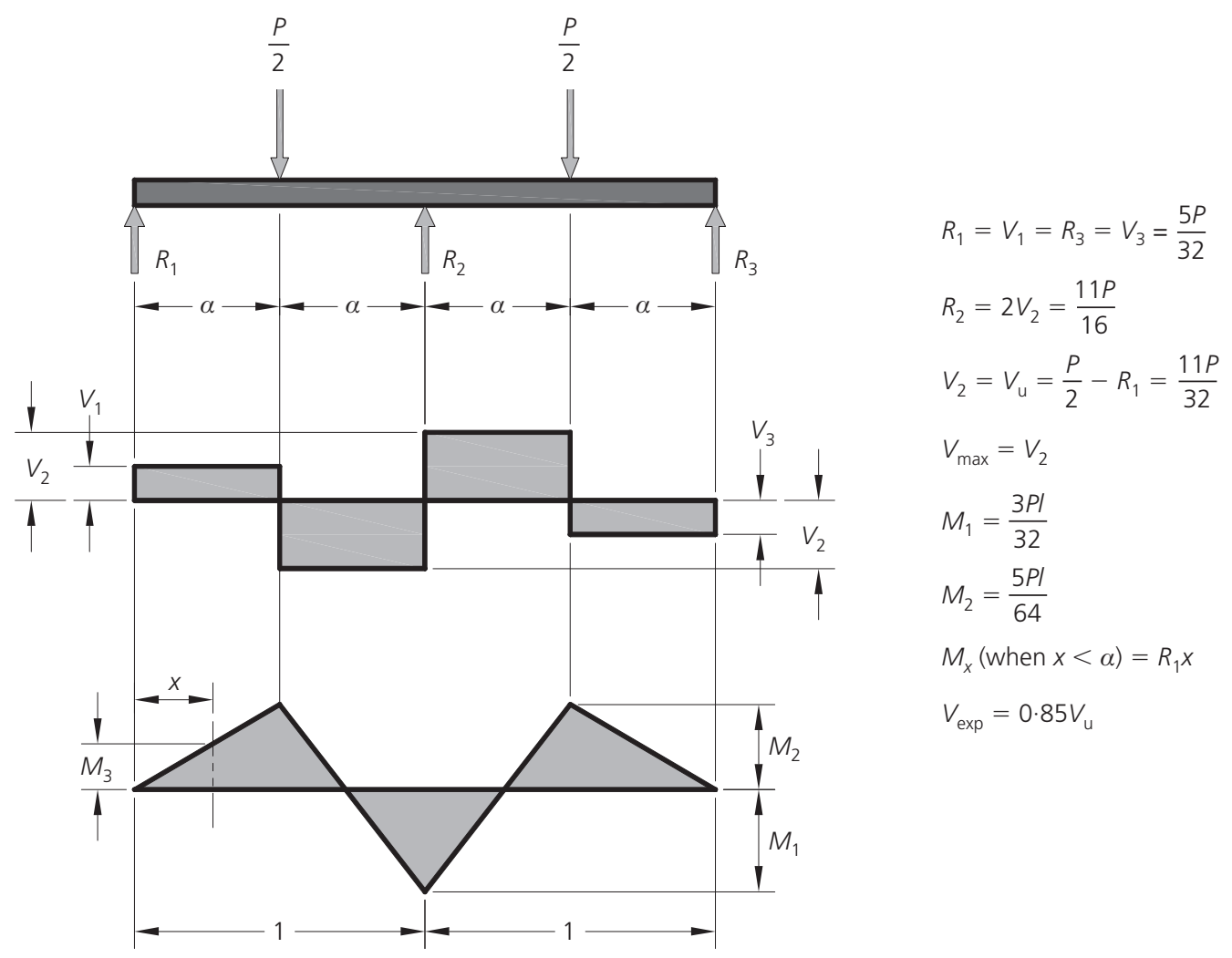

Figure 1. Guidance for different calculations of continuous beam 
Bukhari et al. (2010) reviewed existing design guidelines for strengthening beams in shear with CFRP sheets and proposed a modification to TR55. The results of an experimental programme that evaluated the contribution of CFRP sheets towards the shear strength of continuous RC beams were presented. A total of seven, two-span concrete continuous beams with rectangular cross-sections were tested. Bukhari et al. (2010) proposed a methodology for strengthening beams with FRP that is consistent with Eurocode 2.

\section{Experimental programme}

\subsection{Test specimens}

Five full-scale two-span continuous RC beams of rectangular cross-section $(152.4 \mathrm{~mm}$ by $304.8 \mathrm{~mm})$ and shear span to depth ratio $(a / d)$ of 2.85 were tested. One beam was used as a control specimen and the other four were strengthened in shear using different configurations of CFRP sheets. Three $16 \mathrm{~mm}$ diameter bars were provided throughout the cross-section in all the beams on both faces (top and bottom). The effective depth to the steel reinforcement was $267 \mathrm{~mm}$.

No steel stirrups were provided within the interior shear spans. To ensure shear failure occurred within the central shear spans, $6 \mathrm{~mm}$ diameter steel stirrups were provided in the outer shear spans of the continuous beam at $130 \mathrm{~mm}$ centre to centre (c/c). The beams were not reinforced with internal stirrups within the central shear spans as the aim was to compare the efficiency of different arrangements of CFRP. Rectangular sections were tested, since the aim was to compare the response of continuous beams with that of simply supported rectangular sections tested by other researcher. Details of the beams and reinforcement are shown in Figure 2.

\subsection{Mix proportions}

Portland cement complying with ASTM Type I cement was used, and the coarse aggregate was crushed limestone with a maximum size of $19 \mathrm{~mm}$. Fine and coarse aggregates were from local sources in Pakistan. The proportions of the concrete mix were finalised to $1: 0 \cdot 75: 1 \cdot 75$ by mass of binder, sand and coarse aggregate, respectively. The concrete mix used in the beam specimens had a targeted cylinder strength of $48 \mathrm{MPa}$ at 28 days.

Test beams were cast using two batches of concrete (two and a half beams per batch). The ultimate concrete strength was equal to $50.06 \mathrm{MPa}$. This value is the average of the compressive strength of six cylinders tested at the age of 28 days, three cylinders for each batch. The compressive strength of concrete cylinders was determined as per BS EN 12390-3: 2002 (BSI, 2002). Superplasticiser (Sikament 163) equal to $2 \%$ of weight of cement was added. The workability of the concrete was measured in terms of slump, which was determined for each batch following the procedure laid down in ASTM C 143-78 (ASTM, 1979). The mix proportions are summarised in Table 1 and the physical properties of the aggregates used are reported in Table 2.

\subsection{Strengthening scheme}

The specimen details and the properties of CFRP sheet are given in Table 3. In all the beams except D5, CFRP sheets were bonded to the vertical sides of the beams in the arrangements. Beam D5 was completely wrapped within part of the interior shear spans.

Prior to strengthening, the beam surfaces were cleaned using an electric grinder. The edges of beam D5 were smoothed to reduce stress concentrations at the corners due to the full wrapping of the CFRP sheet. In all the beams, the CFRP sheet was applied with the main fibres oriented perpendicular to the longitudinal axis of the beam. The CFRP sheet was applied with uniform pressure using a surface roller to ensure removal of air bubbles trapped beneath the fabric surface.

\subsection{Test setup}

Each beam was loaded with a concentrated load at the centre of each span. The load was applied using a $1000 \mathrm{kN}$ capacity hydraulic jack with manual control. The beams were loaded progressively, and data were recorded using an automatic data acquisition system. Linear variable displacement transducers (LVDTs) were used to measure vertical displacements at the midspan and over the supports, and strains in the CFRP were also measured on the vertical face of the beam with vertically oriented strain gauges. The strain gauges were located at the mid-depth of all the beams (except D4 beam) at distances of 127, 330 and $533 \mathrm{~mm}$ from the face of the central support. For beam D4, strain gauges were placed at mid-height of the CFRP, keeping the horizontal distances from the face of internal support as in other beams. Cracks and crack pattern were noted at each increment in load. Cracks were marked on each face of the beams throughout testing.

\section{Results and discussion}

\subsection{Failure loads}

Failure loads of all the beams are reported in Table 4 and their failure modes can be seen in Figure 3. Out of the five beams tested, D1 was a control beam and was not strengthened. The first crack appeared at a load of $154 \mathrm{kN}$ directly above the central support. The crack was found to be due to flexural stresses. With an increase of load, the crack pattern changed from flexural to shear. The beam failed completely at a load of $240 \mathrm{kN}$, a result of a shear-tension failure.

Beam D2 was strengthened with CFRP sheets measuring $304.8 \mathrm{~mm}$ by $304.8 \mathrm{~mm}$ applied in the middle of each of the internal shear spans. The first crack was flexural and appeared directly above the central support. This crack was observed at a load of $212 \mathrm{kN}$. The initial cracks developed were noted to be flexural. As loading progressed, shear cracks also became visible. The beam completely failed at a load of $385 \mathrm{kN}(60 \%$ greater than the failure load of control beam D1) due to delamination of the CFRP sheet. Deflection at failure was also more than 7.5 times that achieved in D1. 


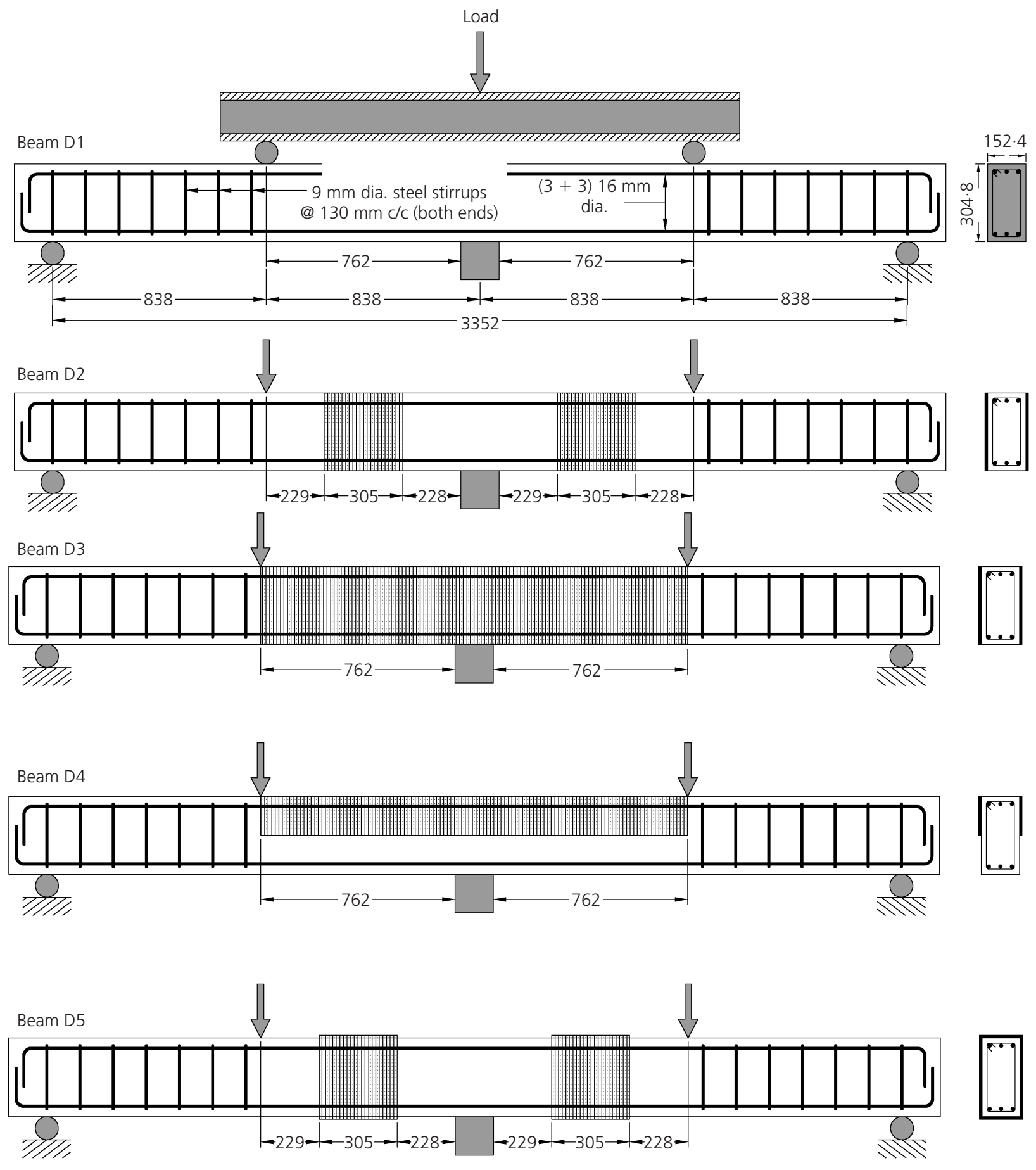

Figure 2. Beam configuration details (dimensions in $\mathrm{mm}$ )

\begin{tabular}{lcccc}
\hline Mix ratio & $\begin{array}{c}\text { Superplasticiser: } \\
\text { \% cement mass }\end{array}$ & w/c & $\begin{array}{c}\text { Slump: } \\
\mathrm{mm}\end{array}$ & $\begin{array}{c}\text { Compressive strength } \\
\text { at 28 days: MPa }\end{array}$ \\
\hline $1: 0 \cdot 75: 1.75$ & 2 & 0.28 & 38 & $50 \cdot 06$
\end{tabular}

Table 1. Mix proportion and properties of mix used 


\begin{tabular}{lcc}
\hline & $\begin{array}{c}\text { Relative density } \\
\text { (saturated surface-dry } \\
\text { condition) }\end{array}$ & $\begin{array}{c}\text { Water } \\
\text { absorption: } \\
\%\end{array}$ \\
\hline Fine aggregate & 2.63 & 1.2 \\
Coarse aggregate & 2.60 & 0.99 \\
Table 2. Properties of aggregates used & \\
\hline
\end{tabular}

Beam D5 was strengthened with a similar configuration of CFRP sheets to beam D2, but the sheets were fully wrapped. The first crack appeared directly above the central support at a load of $212 \mathrm{kN}$. D5 also exhibited shear cracks with an increase in load. Shear cracking appeared at the mid-height of the beam near the central support after clicking sounds were heard in the CFRP sheet; the presence of the CFRP sheet stopped the crack from propagating and led to the formation of a second major diagonal crack between the load point and the CFRP sheet. The second

\begin{tabular}{|c|c|c|c|c|c|c|c|c|c|c|c|}
\hline \multirow[t]{2}{*}{ Beam } & \multirow[t]{2}{*}{$f_{c}^{\prime}: M P a$} & \multirow[t]{2}{*}{$a / d$} & \multirow[t]{2}{*}{$\rho_{\mid}: \%$} & \multicolumn{3}{|c|}{ Section details } & \multicolumn{5}{|c|}{ CFRP properties and wrapping scheme } \\
\hline & & & & $b_{\mathrm{w}}: \mathrm{mm}$ & $h: \mathrm{mm}$ & $h_{\mathrm{f}}: \mathrm{mm}$ & $t_{\mathrm{f}}: \mathrm{mm}$ & $E_{\mathrm{f}}: \mathrm{GPa}$ & $f_{f u}: M P a$ & $\beta:$ deg & Wrapping \\
\hline D1 & 50.06 & $2 \cdot 85$ & $1 \cdot 50$ & $152 \cdot 4$ & $304 \cdot 8$ & - & - & - & - & - & - \\
\hline D2 & $50 \cdot 06$ & $2 \cdot 85$ & $1 \cdot 50$ & $152 \cdot 4$ & $304 \cdot 8$ & $304 \cdot 8$ & 0.34 & $234 \cdot 5$ & 3450 & 90 & Sides \\
\hline D3 & 50.06 & $2 \cdot 85$ & $1 \cdot 50$ & $152 \cdot 4$ & $304 \cdot 8$ & $304 \cdot 8$ & 0.34 & $234 \cdot 5$ & 3450 & 90 & Sides \\
\hline D4 & 50.06 & $2 \cdot 85$ & $1 \cdot 50$ & $152 \cdot 4$ & $304 \cdot 8$ & $152 \cdot 4$ & 0.34 & $234 \cdot 5$ & 3450 & 90 & Sides \\
\hline D5 & 50.06 & 2.85 & $1 \cdot 50$ & $152 \cdot 4$ & $304 \cdot 8$ & $304 \cdot 8$ & 0.34 & 234.5 & 3450 & 90 & Wrap \\
\hline
\end{tabular}

Table 3. Specimen details and CFRP properties

\begin{tabular}{lrrrrl}
\hline Beam & $P_{\mathrm{u}}: \mathrm{kN}$ & $V_{\text {exp }}: \mathrm{kN}$ & $V_{\mathrm{f}}: \mathrm{kN}$ & $\begin{array}{c}\text { Mid-span } \\
\text { deflection: } \mathrm{mm}\end{array}$ & Failure mode \\
\hline D1 & 240.45 & 70.26 & - & 0.41 & Shear \\
D2 & 384.65 & 112.39 & $42 \cdot 13$ & $3 \cdot 14$ & Sheet delamination \\
D3 & 415.11 & 109.58 & 39.32 & 3.27 & Sheet delamination \\
D4 & 307.69 & 89.90 & 19.64 & $2 \cdot 16$ & Sheet delamination \\
D5 & 423.15 & 123.64 & 53.38 & 5.49 & Sheet rupture
\end{tabular}

Table 4. Experimental results

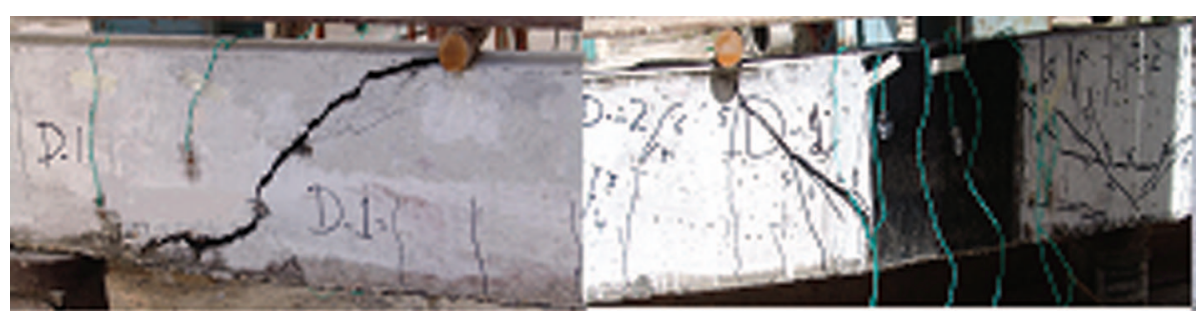

Beam D-1
Beam D-2

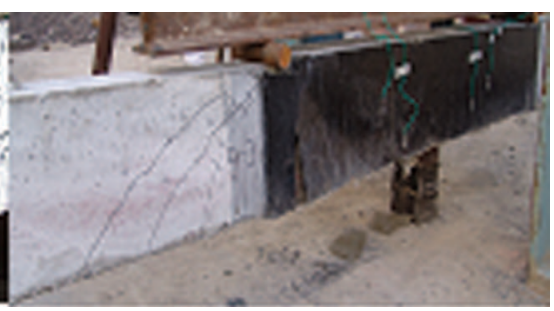

Beam D-3

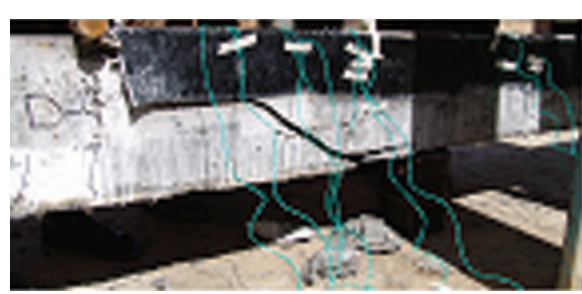

Beam D-4

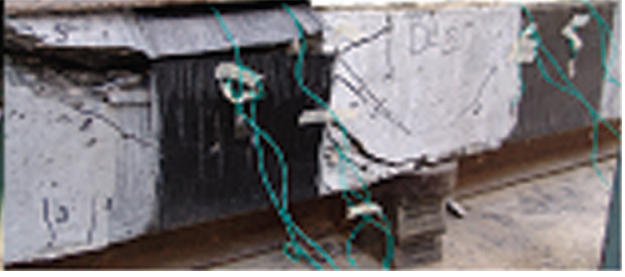

Beam D-5

Figure 3. Cracks patterns developed in beam D1 (a), D2 (b),

D3 (c), D4 (d) and D5 (e) 
crack propagated along the tensile reinforcement towards the central support. Failure occurred at a load of $423 \mathrm{kN}$. Delamination of the CFRP sheet was observed on both sides of the beam, but the beam failed as a result of CFRP sheet rupturing along with concrete splitting at the bottom face of the beam. Comparison of D5 with control beam D1 shows that the load-carrying capacity was $76 \%$ greater than that of D1. The shear failure process in D5 started with debonding of the CFRP from the sides of the beam near the critical shear crack (which was seen after failure and removing the wrap), but ultimate failure was by rupture of the CFRP. However, debonding of CFRP from the sides is at least a serviceability limit state and may also be taken as the ultimate limit state. Strain values were measured at the CFRP debonding stage in Beam D5. Deflection at failure was 13 times greater than that of control beam D1. The deflection of the beam and the strain in the CFRP sheet were also greater than those in beam D2.

Beam D3 was strengthened by complete side wrapping with CFRP sheets in the internal shear spans as shown in Figure 2. Initially, minor flexural cracks appeared in the top face of the beam above the central support. During the test, clicking sounds were heard due to the formation of probable cracks in the side faces of the beam, which were unseen due to CFRP wrapping. As the load increased, delamination occurred between the concrete and the CFRP sheet under the load point. The beam failed at $375 \mathrm{kN}, 73 \%$ greater than that of control beam D1, due to delamination of the CFRP sheet. A longitudinal crack was also observed at the top face of the beam, indicative of a splitting failure. After the test, the CFRP sheet was removed. The crack pattern was considerably different from the other beams in that the failure crack travelled along the bottom steel reinforcement, which is consistent with the arching action observed in the test. Loss of bond occurred between the steel reinforcement and the concrete, resulting in separation of the concrete cover. Deflection at failure was observed to be considerably higher (5.27 times) than that noted for the control beam. Comparison of beams D3 and D2 shows marginal strength improvements in D3. An increase in load-carrying capacity $(21 \%)$ as well as deflection enhancement was observed. This indicates that the surface area of the CFRP sheet can be minimised while maintaining a considerable increase in shear capacity.

Beam D4 was strengthened with CFRP sheets applied to the top (tensile) half of the beam depth in the internal shear spans, as shown in Figure 2. CFRP sheet was applied to both side surfaces of the beam in the negative moment region. Cracking originated because of flexural stresses at a load of $192 \mathrm{kN}$. The crack position was again directly above the central support. Delamination of the CFRP sheet in the middle of the interior shear span was observed. This occurred due to the formation of a critical diagonal crack at a failure load of $308 \mathrm{kN}$, which is $28 \%$ greater than the control beam. The deflection at failure was $5 \cdot 2$ times that of the control beam. Comparison with beams D2 and D3 shows that the load-carrying capacity and deflection decreased in the case of D4. The combination of a critical diagonal crack and concrete cover separation made the beam more brittle than the other CFRP-strengthened beams. This increased brittleness could also be due to strengthening only the top half of the beam, leading to more stress concentration compared with that in the CFRP sheets used on the other beams. Of the strengthened beams, D4 also showed the least deformation before failure.

\subsection{Shear strength}

Table 4 shows that the shear strength of continuous RC beams can be significantly enhanced by strengthening with externally bonded CFRP sheets. Figure 2 shows that there is a considerable reduction $(63 \%)$ in the surface area of CFRP sheet applied in beam D2 compared with that in beam D3. However, the shear contribution of the CFRP of beam D2 was only $15 \%$ less than that of beam D3 with a complete side wrap. Favourable results can also be achieved with less surface area of CFRP depending on the configuration of the CFRP, steel stirrups and load conditions. The surface area of CFRP sheet can thus be minimised without great loss in shear carrying capacity.

Shear strengthening of continuous beams within the negative moment region (i.e. beam D4) was found to be effective in terms of strength increase and reduction in the area of CFRP, but resulted in a brittle failure mode. Of all the CFRP-strengthened beams, the more brittle behaviour of beam D4 could be due to strengthening only the top half of the beam, leading to more stress concentration compared with the other beams. This type of CFRP strengthening is, therefore, not recommended.

Applying CFRP sheet within the middle half of the shear span (e.g. beam D2 where strength was increased by $60 \%$ ) was found to be effective for continuous beams with ratios of shear span to effective depth of 2.85. However, proper end anchorage is required to achieve maximum utilisation of the CFRP, as the beam D5 with complete wrapping of CFRP showed a $76 \%$ increase in shear strength. It was also found that the presence of CFRP sheet resisted crack propagation and altered the crack pattern from that observed in the control beam (Figure 3).

\subsection{Load-deflection behaviour}

The experimental results in Table 4 and the load-mid-span deflection data plotted in Figure 4 show that control beam, D1, was considerably stiffer than all the CFRP-strengthened beams. The deflections of all the strengthened beams at ultimate load were greater than that of the control beam. The largest deflection was observed in beam D5, with complete CFRP wrapping. During testing, it was noted that D1, D2 and D4 exhibited brittle behaviour, whereas the other beams failed in a relatively ductile mode; this might be because the load capacity of D1, D2 and D4 would have been reached with little inelastic deformation. There is usually no clear yield point in CFRP-strengthened beams. However, Mukhopadhyaya et al. (1998) suggested that deflection can be used as one of the criteria of ductility to evaluate comparative structural performance of CFRP-bonded RC beams. 


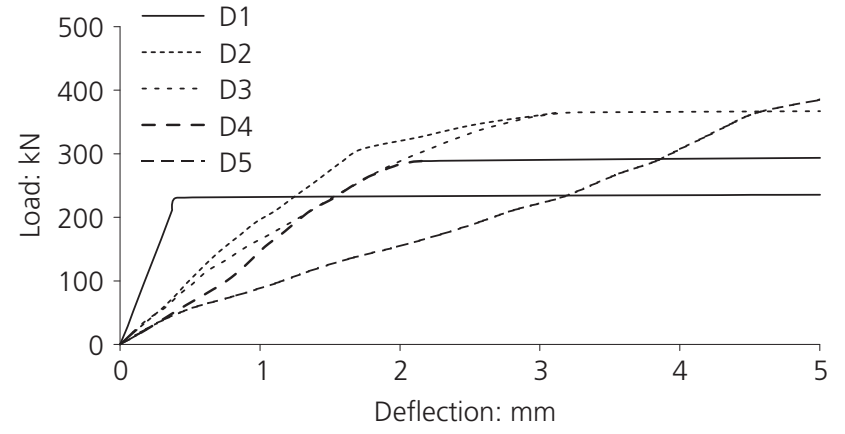

Figure 4. Load-mid-span deflection curves of beams

Increased deflection in D3 and D5 could be due to considerable post-yield elongation of the existing steel reinforcement. The current study also showed the possibility of transforming a brittle failure mode to relatively ductile failure by changing CFRP arrangements.

During testing of beams D3 and D5, the CFRP sheets also showed good response to additional loading beyond the initial shear crack, and eventually failed after warning signs such as snapping sounds and peeling of the CFRP. With the CFRP sheet arrangements in D3 and D5, these beams exhibited a relatively smaller crack spacing and size, increased mid-span deflection and greater effective strain in the CFRP sheet at failure. The CFRP arrangements in D3 and D5 might have provided redistribution of stresses in the beam (El-Mogy et al., 2011), resulting in more favourable ductile behaviour with ample warnings before failure.

\subsection{Load-strain behaviour}

Figure 5 shows the variation in vertical strain in the CFRP sheet, with shear force, at the mid-depth of the beam at the centre of the failed shear span. In all the beams, the peak strains measured in the CFRP were less than the ultimate strain of CFRP at failure. It was found that the value of strain was very small prior to the development of a diagonal crack, after which a rapid increase in strain was observed. The greatest CFRP strains, and hence maximum utilisation of the CFRP sheet strength, were measured in beam D5, in which the CFRP sheet was applied as a complete wrapping.

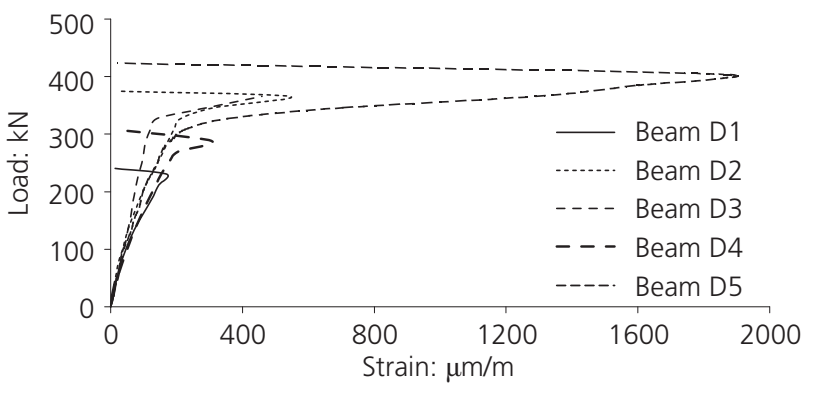

Figure 5. Load-vertical strain in CFRP sheet (mid-depth)

\subsection{Analysis of beams}

Table 5 compares the experimental strain reduction factors $\left(R_{\exp }\right)$ and the reduction factors predicted by other models. The experimental reduction factors were obtained by dividing the measured strain in the CFRP by the ultimate strain. The calculated $R$ values for beam D2 range from $0 \cdot 17$ to $0 \cdot 30$, whereas the experimental value is 0.08 . The reason for this difference may be due to premature debonding of the CFRP sheet in beam D2. Similarly, for beam D5, which failed due to rupture of the CFRP sheet, the model predictions are higher than the experimental factor. Comparison of the values in Table 5 shows that the model proposed by Bukhari et al. (2010) gives relatively good predictions for the other beams.

All the models showed reasonable predictions for beams D3 and D5. However, most of the models overestimated the strain predictions for the beams D2 and D4. This could be due to the brittle behaviour of these beams, which exhibited less deformation before failure. TR55 overestimated the results for all the beams. This could be because of not relating the effective strain in CFRP to its axial rigidity in the proposed equations. Consequently, TR55 was found significantly to overestimate $V_{\mathrm{f}}$ in some beams, including those tested in this work and by Pelligrino and Modena (2002). Therefore, it is suggested that TR55 should be modified to rectify the equations to relate the effective strain in CFRP to its axial rigidity in side and U-wrapped sections.

The shear strength contribution of FRP sheets $\left(V_{\mathrm{f}}\right)$ was calculated by subtracting the shear strength of the control beam from the shear capacity of the CFRP-strengthened beam. The measured and predicted values of $V_{\mathrm{f}}$ are compared in Table 6, which shows that all the models predicted well for beams D2 and D5 but overestimated for beams D3 and D4. This could be because D4 was deficient in CFRP side wrapping and the full side wrapping of CFRP in D3 did not play its full role. Less experimental shear strength contribution was observed for increased CFRP surface area as compared with beam D2. A comparison of the experimental results indicates that the shear strength predictions of all the models are conservative, but the model proposed by Bukhari et al. (2010) is most accurate. This is attributed to the fact that the beams in this study were cast and tested under the same conditions as in the work of Bukhari et al. (2010), although compressive strength was the main difference in the studies.

\begin{tabular}{lcccccc}
\hline Beam & $R_{\mathrm{T}}$ & $R_{\mathrm{K}}$ & $R_{\mathrm{Z}}$ & $R_{\mathrm{TR} 55}$ & $R_{\mathrm{B}}$ & $R_{\exp }$ \\
\hline D2 & 0.30 & 0.22 & 0.22 & 0.27 & 0.09 & 0.08 \\
D3 & 0.18 & 0.12 & 0.16 & 0.27 & 0.17 & 0.18 \\
D4 & 0.18 & 0.12 & 0.16 & 0.27 & 0.09 & 0.12 \\
D5 & 0.30 & 0.30 & 0.22 & 0.27 & 0.17 & 0.21
\end{tabular}

Table 5. Comparison of strain reduction factors $\left(R=\varepsilon_{\mathrm{fe}} / \varepsilon_{\mathrm{fu}}\right)$ 


\begin{tabular}{|c|c|c|c|c|c|c|c|c|c|c|c|}
\hline \multirow[t]{2}{*}{ Beam } & \multirow[t]{2}{*}{$V_{f}: k N$} & \multicolumn{2}{|c|}{$\begin{array}{c}\text { Triantafillou and } \\
\text { Antonopoulos (2000) }\end{array}$} & \multicolumn{2}{|c|}{$\begin{array}{c}\text { Khalifa et al. } \\
\text { (1998) }\end{array}$} & \multicolumn{2}{|c|}{$\begin{array}{l}\text { Zhang and Hsu } \\
\qquad(2005)\end{array}$} & \multicolumn{2}{|c|}{$\begin{array}{l}\text { TR55 (Concrete } \\
\text { Society, 2004) }\end{array}$} & \multicolumn{2}{|c|}{$\begin{array}{l}\text { Bukhari et al. } \\
\qquad(2010)\end{array}$} \\
\hline & & $V_{\mathrm{fT}}: \mathrm{kN}$ & $V_{\mathrm{f}} / V_{\mathrm{fT}}$ & $V_{\text {fk }}: k N$ & $V_{\mathrm{f}} / V_{\mathrm{fk}}$ & $V_{\mathrm{fz}}: \mathrm{kN}$ & $V_{\mathrm{f}} / V_{\mathrm{fz}}$ & $V_{\text {fTR55 }}: \mathrm{kN}$ & $V_{f} / V_{\text {FTR55 }}$ & $V_{\mathrm{fB}}: \mathrm{kN}$ & $V_{\mathrm{f}} / V_{\mathrm{fB}}$ \\
\hline D2 & $43 \cdot 4$ & $53 \cdot 77$ & 0.81 & $55 \cdot 74$ & 0.78 & $56 \cdot 57$ & 0.77 & $43 \cdot 72$ & 0.99 & $39 \cdot 17$ & $1 \cdot 11$ \\
\hline D3 & $52 \cdot 5$ & $80 \cdot 45$ & 0.65 & $75 \cdot 45$ & 0.70 & 99.88 & 0.53 & $108 \cdot 34$ & 0.48 & $51 \cdot 56$ & 1.02 \\
\hline D4 & $20 \cdot 3$ & $45 \cdot 95$ & 0.44 & $43 \cdot 10$ & 0.47 & 57.05 & 0.36 & $41 \cdot 47$ & 0.49 & $29 \cdot 45$ & 0.69 \\
\hline D5 & 54.9 & $58 \cdot 25$ & 0.94 & 76.65 & 0.72 & $56 \cdot 57$ & 0.97 & 62.94 & 0.87 & 39.17 & 1.40 \\
\hline SD & & & 0.22 & & 0.13 & & 0.27 & & 0.26 & & 0.29 \\
\hline Mean & & & 0.71 & & 0.67 & & 0.65 & & 0.71 & & 1.05 \\
\hline
\end{tabular}

Table 6. Comparison of experimental results with different models, showing standard deviation (SD) and mean

The experimental results indicate that CFRP sheets can be effectively used to enhance the shear capacity of continuous RC beams. However, the contribution varies depending upon the CFRP configuration. Moreover, the surface area of CFRP can be substantially minimised while still achieving improved shear carrying capacity of the concrete beams. It is generally considered that the application of CFRP sheet along the entire shear span results in increased shear carrying capacity, and this was confirmed by the tests on beam D3. However, the experimental results also showed that the application of CFRP in the middle half of the shear span (beams D2 and D5) results in significantly improved shear carrying capacity with a considerably reduced area of the sheet (and, therefore, significant reduction in cost) for an appropriate configuration scheme.

\section{Conclusions}

- Favourable results can be achieved with a reduced surface area of CFRP depending on the configuration of the CFRP, steel stirrups and load conditions. Due to an extremely brittle failure mode, shear strengthening of continuous beams only in the negative moment region (beam D4) is not recommended.

- The presence of CFRP sheet alters the cracking pattern of a strengthened RC beam, which suggests careful consideration of the CFRP sheet configuration is required.

- The mid-span deflection (at maximum load) of CFRP-strengthened beams was found to be higher than that of the control beam.

- Due to variations that can occur during testing, a larger number of tests for each configuration would be helpful. Deeper analysis of the same situations would strengthen the conclusions made.

\section{REFERENCES}

ACI (American Concrete Institute) (1996) ACI Committee 440: State-of-the-art report on fiber reinforced plastic reinforcement for concrete structures. ACI, Detroit, MI, USA, Report ACI 440R-96.
ACI (2002) ACI Committee 440: Guide for the design and construction of externally bonded FRP systems for strengthening concrete structures. ACI, Farmington Hills, MI, USA.

Al-Amerya R and Al-Mahaidi R (2006) Coupled flexural-shear retrofitting of RC beams using CFRP straps. Composite Structures 75(1): 475-464.

Ashour AF, El-Refaie SA and Garrity SW (2004) Flexural strengthening of RC continuous beams using CFRP laminates. Cement \& Concrete Composites 26(7): 765-775.

ASTM (1979) Standard test method for slump of Portland cement concretes. In 1979 Annual Book of ASTM Standards. ASTM, Philadelphia, PA, USA, pt 14, pp. 97-98.

Berset JD (1992) Strengthening of Reinforced Concrete Beams for Shear Using Composites Materials. MSc thesis, MIT, Cambridge, MA, USA.

BSI (2002) Testing hardened concrete. Compressive strength of test specimens. BS EN 12390-3: 2002. BSI, London, UK.

BSI (2004) Eurocode 2. Design of concrete structures - Part 1-1: General rules and rules for buildings. BS EN 1992-1-1. BSI, London, UK.

Bukhari IA, Ahmad S, Vollum RL and Sagaseta J (2010) Shear strengthening of reinforced concrete beams with CFRP. Magazine of Concrete Research 62(1): 65-77.

Chajes MJ, Januska TF, Mertz DR, Thomson TA and Finch WW (1995) Shear strengthening of reinforced concrete beams using externally applied composite fabrics. ACI Structural Journal 92(3): 295-303.

Chen JF and Teng JG (2002) Shear capacity of FRP-strengthened RC beams: FRP rupture. Journal of Structural Engineering 129(5): 615-625.

Concrete Society (2000) Design guidance for strengthening concrete structures using fibre composite materials. Technical Report No. 55. Concrete Society, Camberley, UK.

Concrete Society (2004) Design Guidance for Strengthening Concrete Structures using Fibre Composite Materials, 2nd edn. Concrete Society, Camberley, UK TR55.

Denton SR, Shave JD and Porter AD (2004) Shear strengthening 
of reinforced concrete structures using FRP composites. In Advanced polymer composites for structural applications in construction (Holloway LC, Chrissanthopoulos MK and Moy SSJ (eds)). Woodhead, Cambridge, UK, pp. 134-143.

Duthinh D and Starnes M (2004) Strength and ductility prediction of concrete beams reinforced with carbon fiber-reinforced polymers plates and steel. ASCE Journal of Composites for Construction 8(1): 59-69.

El-Mogy M, El-Ragaby A and El-Salakawy E (2011) Flexural behavior of continuous FRP-reinforced concrete beams. ASCE Journal of Composites for Construction, http:// dx.doi.org/10.1061/(ASCE)CC.1943-5614.0000140.

fib (2001) Externally bonded FRP reinforcement for RC structures. fib Bulletin 14. Technical Report of Working Party EBK of Task Group 9.3 of the International Federation for Structural Concrete.

Hassan T and Rizkalla S (2004) Bond mechanism of near-surfacemounted fiber-reinforced polymer bars for flexural strengthening of concrete structures. ACI Structural Journal 101(6): 830-839.

Khalifa A and Nanni A (2002) Rehabilitation of rectangular simply supported RC beams with shear deficiencies using CFRP composites. Construction and Building Materials 16(3): 135-146.

Khalifa A, Gold W, Nanni A and Abdel-Aziz MI (1998) Contribution of externally bonded FRP to the shear capacity of RC flexural members. Journal of Composites for Construction 2(4): 195-202.

Malek A and Saadatmanesh H (1998) Ultimate shear capacity of reinforced concrete beams strengthened with web-bonded fiber-reinforced plastic. ACI Structural Journal 95(4): $391-$ 399.

Mukhopadhyaya P, Swamy N and Lynsdale C (1998) Optimizing structural response of beams strengthened with GFRP plates. Journal of Composites for Construction 2(2): 87- 95.

Pelligrino C and Modena C (2002) Fiber reinforced polymer shear strengthening of reinforced concrete beams with transverse reinforcement. Journal of Composites for Construction 6(21): 104-111.

Triantafillou TC (1998) Shear strengthening of reinforced concrete beams using epoxy-bonded FRP composites. ACI Structural Journal 95(2): 107-115.

Triantafillou TC and Antonopoulos CP (2000) Design of concrete flexural members strengthened in shear with FRP. Journal of Composites for Construction 4(4): 198-205.

Uji K (1992) Improving shear capacity of existing reinforced concrete members by applying carbon fiber sheets.

Transactions of the Japan Concrete Institute 14: 253-266.

Zhang Z and Hsu T (2005) Shear strengthening of reinforced concrete beams using carbon-fiber-reinforced polymer laminates. Journal of Composites for Construction 9(2): $158-169$.

\section{WHAT DO YOU THINK?}

To discuss this paper, please email up to 500 words to the editor at journals@ice.org.uk. Your contribution will be forwarded to the author(s) for a reply and, if considered appropriate by the editorial panel, will be published as a discussion in a future issue of the journal.

Proceedings journals rely entirely on contributions sent in by civil engineering professionals, academics and students. Papers should be 2000-5000 words long (briefing papers should be 1000-2000 words long), with adequate illustrations and references. You can submit your paper online via www.icevirtuallibrary.com/content/journals, where you will also find detailed author guidelines. 